\title{
Adsorption of amino acids on MFI-type zeolite: DFT calculations and experimental results
}

\author{
Kai Stueckenschneider ${ }^{1 *}$, Achim Zielesny ${ }^{2}$, Gerhard Schembecker $^{1}$ \\ From 7th German Conference on Chemoinformatics: 25 CIC-Workshop \\ Goslar, Germany. 6-8 November 2011
}

Adsorption is a common unit operation in separation and purification of biotechnological products where chromatography steps can make up more than half the amount of the total purification costs [1]. The molecular mechanisms of adsorption are still not understood in detail. Further understanding of interactions between adsorbent surfaces and adsorptives could help to facilitate process design in a more cost efficient manner.

In this work the interaction of MFI-type zeolite MFI$27(\mathrm{Al} / \mathrm{Si}=13)$ with Alanine and Phenylalanine is investigated by quantum chemical (QM) calculations which are compared to experimental adsorption data.

For the QM calculations T3-clusters are used as MFI27 surface models which were shown to be successful e. g. in the case of protolytic cracking of alkanes [2,3]. In order to model different $\mathrm{pH}$-values Alanine and Phenylalanine are applied in their protonated, zwitterionic and deprotonated state. Geometry optimisations and frequency analysis of all molecular structures are performed with Density Functional Theory (DFT) using the B3LYP functional with different basis sets. Calculated complex energies are corrected for BSSE and ZPE. Adsorption isotherms are derived from corresponding experiments.

Regarding the adsorption isotherms it is shown that a high adsorption of Alanine and Phenylalanine on MFI27 takes place at low $\mathrm{pH}$ values (near the $\mathrm{pK}_{\mathrm{a}}$ of the amino acids). Less adsorption occurs with an increased $\mathrm{pH}$ equalling the amino acids' isoelectric points. At the $\mathrm{pH}$ of the amico acids' $\mathrm{pK}_{\mathrm{b}}$ values adsorption is no longer observed.

These trends can be correlated with the corresponding QM calculations. High binding energies are calculated

\footnotetext{
* Correspondence: Kai.Stueckenschneider@bci.tu-dortmund.de 'Department of Biochemical and Chemical Engineering, TU Dortmund, Dortmund, 44227, Germany

Full list of author information is available at the end of the article
}

for the protonated amino acids. Zwitterionic states lead to lower binding energies. The deprotonated amino acids do not show any binding affinity to MFI-27.

These first results indicate the reliability of the applied methods for our model system.

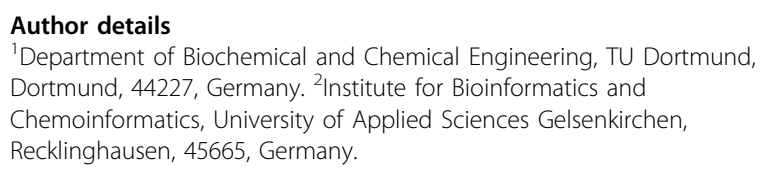

Published: 1 May 2012

\section{References \\ 1. Ladisch MR: Bioseparations Engineering. Wiley and Sons; 2001, 1-5. \\ 2. Zheng X, Blowers P: Reactivity of Alkanes on Zeolites: A Computational Study of Propane Conversion Reactions. J Phys Chem A 2005, 109:10734-10741. \\ 3. Zheng X, Blowers P: Reactivity of Isobutane on Zeolites: A First Principles Study. J Phys Chem A 2006, 110:2455-2460.}

doi:10.1186/1758-2946-4-S1-P38

Cite this article as: Stueckenschneider et al:: Adsorption of amino acids on MFI-type zeolite: DFT calculations and experimental results. Journal of Cheminformatics 2012 4(Suppl 1):P38. 